\title{
Malate Dehydrogenase allele frequencies in the commercial honey bee (Apis mellifera) population in Thailand reflect those in source populations
}

\author{
Thitipan Meemongkolkiat $^{\mathrm{a}, \mathrm{b}, *}$, Julianne Lim $^{\mathrm{b}}$, Chanpen Chanchao ${ }^{\mathrm{c}}$, Benjamin P. Oldroyd ${ }^{\mathrm{b}}$ \\ a Program in Biotechnology, Faculty of Science, Chulalongkorn University, Bangkok 10330 Thailand \\ b Behaviour and Genetics of Social Insects Laboratory, School of Life and Environmental Sciences, \\ University of Sydney, NSW 2006 Australia \\ c Department of Biology, Faculty of Science, Chulalongkorn University, Bangkok 10330 Thailand
}

*Corresponding author, e-mail: lek_tues_ti@hotmail.com

\begin{abstract}
In the western honey bee (Apis mellifera) populations, cytosolic malate dehydrogenase (cMDH) allele frequencies are correlated with the environmental temperatures. The Slow and Fast alleles predominate in hot climates; the Medium allele predominates in cold climates. We wondered whether natural selection has had anything to do with the Medium allele in the imported exotic A. mellifera population in Thailand. We genotyped workers $(\mathrm{n}=1032)$ from 86 commercial colonies from three regions. Three alleles: Fast, Medium, and Slow, were detected. Over 96\% of the Thai A. mellifera are either homozygous for the Slow or heterozygous for the Fast allele; and the Medium allele has the lowest frequency (c.a. 10\%) in all sampled population. This might be indicative of selection against the Medium allele. However, as the cMDH allele frequencies in the Thai $A$. mellifera are similar to those seen in the source populations in the United States and Northern Italy, it might also be that the observed frequencies are reflective of frequent imports from the United States, and that natural selection is unable to overcome the effects of migration.
\end{abstract}

KEYWORDS: Apis mellifera, cytosolic malate dehydrogenase, honey bee import, temperature clines

\section{INTRODUCTION}

Cytosolic malate dehydrogenase (hereafter, cMDH) is a metabolic enzyme that catalyzes the interconversion of malate and oxaloacetate [1]. It plays a central role in several metabolic pathways including amino acid synthesis and gluconeogenesis $[1,2]$. In many organisms, cMDH has different forms (allozymes) due to polymorphisms in its amino acid sequences. Because of its reliable polymorphism, cMDH was an important contributor to early population genetic studies based on allozyme electrophoresis.

Interestingly, different cMDH allozymes often have different thermostabilities across a range of species [3-5], and this can lead to clines in which the frequency of cMDH alleles is correlated with average environmental temperatures [6-8]. For example, in a serendipitous 'natural' experiment, discharge of cooling water from a power plant into a lake changed the average $\mathrm{cMDH}$ allele frequencies in the largemouth bass (Micropterus salmoides) population of the lake $[9,10]$. The $c M D H-B^{2}$ allele predominated in the area near the powerplant discharge point, where the water temperature remains warm throughout the year, but remained rare elsewhere in the lake [7].

cMDH of the honey bee, Apis mellifera, has three main allozymes designated Fast, Medium, and Slow based on their movements under electrophoresis $[11,12]$. In vitro studies have shown that the three alleles have different thermostabilities [5], and that these differences are due to differing numbers of cation and hydrogen bonds between the amino acid residues of the molecule [13]. The Medium allele has the lowest thermostability and the lowest catalytic capacity at high temperatures, but it likely has the highest catalysis at low temperatures [13]. The Fast and, particularly, the Slow alleles are more resistant to heat denaturation and have higher catalytic activity at high temperatures $\left(>50^{\circ} \mathrm{C}\right)$ than the Medium allele. These differences in thermostability and catalytic activity are often manifest at the population level. Clines in honey bee $\mathrm{cMDH}$ allele frequencies have been documented on four continents $[8,14,15]$ with the Medium allele at the highest frequency in cooler areas. Indeed, the Medium allele is fixed or nearly so in Alpine France [14] and Norway [16]. This is a strong piece of evidence that the honey bee $\mathrm{cMDH}$ locus is under natural selection in the wild [17].

Apis mellifera was first introduced to Thailand in 1940, and again in 1953, for research purposes [18]. Since 1970, large numbers of A. mellifera have been regularly imported from the United States, Australia, and Taiwan for commercial purposes [19]. Today, A. mellifera is widespread, particularly in the Northern Provinces of Chiang Mai and Chiang Rai which have 79810 and 31740 colonies, respectively (data obtained from Agricultural Technology Promotion center (economic insects) Chiang Mai Province), and there are more than 300000 colonies country-wide [19].

Thailand is a tropical country, suggesting that the 


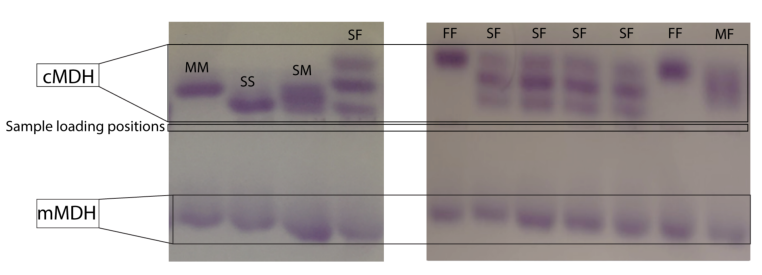

Fig. 1 Cellulose acetate gel electrophoresis of cytosolic malate dehydrogenase (cMDH) from A. mellifera after staining with $\mathrm{cMDH}$ staining mixtures; $\mathrm{mMDH}=$ mitochondrial MDH.

cMDH of the heat-sensitive Medium allele would be at a selective disadvantage relative to the Fast and the Slow alleles and, consequently, would now be at low frequency. To test this hypothesis, we assessed the distribution of $\mathrm{cMDH}$ alleles from different areas in Thailand.

\section{MATERIALS AND METHODS}

\section{Specimen collection}

Adult workers were collected from 86 colonies in 11 provinces in three regions of Thailand: the North, the North-east, and the South, during March 2017January 2018. Details of the collection sites and number of colonies sampled per site are provided in Fig. S1 and Table S1. The samples were obtained from areas ranging from $8^{\circ} 46^{\prime} 42.2^{\prime \prime} \mathrm{N}$ to $19^{\circ} 10^{\prime} 35.0^{\prime \prime} \mathrm{N}$ latitude and $98^{\circ} 48^{\prime} 12.4^{\prime \prime} \mathrm{E}$ to $103^{\circ} 00^{\prime} 06.5^{\prime \prime} \mathrm{E}$ longitude. Twelve adult workers per colony were used for $\mathrm{cMDH}$ genotyping (1032 bees in total). The climatic data (mean monthly minimum and maximum temperatures for January and May) of each region were obtained from the online data of the Thai Meteorological Department. All samples were collected from commercial apiaries at multiple sites per province. Adult bees were randomly sampled from honey combs at least three hives per apiary. Sampled bees were immediately frozen on dry ice, and stored at $-80^{\circ} \mathrm{C}$ in the laboratory until processing.

\section{Allozyme analysis and population study}

The cMDH genotype of individual bees was determined using cellulose-acetate gel electrophoresis at $200 \mathrm{~V}$ for $20 \mathrm{~min}$ in the electrophoresis tank (Helena Laboratories, Texas, USA). The electrophoresis buffers and the histological stains used for the detection of protein bands were according to those previously described $[13,20]$. Fig. 1 shows the typical banding patterns of the selected genotypes. The staining procedure unambiguously identifies the cMDH protein, and no other proteins are stained.

Allele and genotype frequencies were determined for the individual regions and the overall area. Allelefrequency based population genetic statistics, including observed (Ho) and expected ( $\mathrm{He}$ ) (assuming ran- dom mating) heterozygosities, $F_{\text {IS }}$ within regions, and $F_{\mathrm{ST}}$ between regions, were calculated using GenAlEx 6.5 [21]. $F_{\mathrm{ST}}$ is the measure of subpopulation genic differentiation between regions [22]; $F_{\mathrm{IS}}$ is the proportion of the variance in the subpopulation contained within regions [22].

\section{RESULTS AND DISCUSSION}

The electrophoretic patterns of the cMDH locus in A. mellifera from Thailand are in keeping with honey bees from various countries that the cMDH locus is controlled by the three alleles: Fast, Medium, and Slow $[5,11,15]$. Homozygous bees contain a single major band and heterozygous bees three major bands. The middle band in heterozygous bees results from the dimeric nature of cMDH (Fig. 1).

The observed (Ho) and the expected ( $\mathrm{He}$ ) heterozygosities were similar, suggesting a selectively neutral locus and limited population structuring as indicated by the low FST between regions (Table 2). The Medium allele had the lowest frequency in all three regions (Tables 1 and 2), potentially an indicative of selection against the Medium allele. However, the $\mathrm{cMDH}$ allele frequencies of the Thai A. mellifera are similar to those observed in the queen breeding population in the United States [23] and Northern Italy [14] (see Table 2).

Although, temperature clines in honey bee $\mathrm{cMDH}$ allele frequencies in many countries provide strong evidence that $\mathrm{cMDH}$ experiences natural selection in the wild $[8,17]$. However, it is likely that the queen trades, the colony migrations, and possibly the new introductions also have an impact on allele frequencies. In Guatemala and Mexico, commercial beekeepers and queen breeders introduced bees with the Fast allele resulting high frequencies of the Fast allele [24]. The A. mellifera in Brazil shifted strongly toward the Fast allele as a result of the introduction of African subspecies in the 1950s [11].

The distribution of $\mathrm{cMDH}$ allele frequencies of A. mellifera in Thailand are similar to those found in the source populations in the United States [23] and Northern Italy [14]. Therefore, we have no evidence that natural selection is selecting against the Medium allele over time. Perhaps, there has been insufficient time for the Medium allele to decline in frequency, but we suggest that frequent imports from the United States probably counter the effects of selection. However, the frequency of homozygous MM bees is less than $2 \%$, suggesting natural selection because a colony is little disadvantaged by having a small number of bees of this genotype.

cMDH allele and genotype frequencies were normalized using the arcsine square root transformation [25]. There was no significant correlation between the allele or genotype frequencies and the average minimum or maximum temperatures across the 
Table 1 The number of $A$. mellifera cytosolic malate dehydrogenase (cMDH) genotypes samples in the three regions of Thailand. The numbers in parentheses are the genotypes frequencies.

\begin{tabular}{lccrrrrr}
\hline Region & $\mathrm{n}$ & \multicolumn{7}{c}{ Genotype $^{*}$} \\
\cline { 3 - 8 } & & \multicolumn{1}{c}{ SS } & SM & \multicolumn{1}{c}{ SF } & \multicolumn{1}{c}{ MM } & \multicolumn{1}{c}{ MF } & FF \\
\hline Northern & 348 & $171(0.52)$ & $45(0.16)$ & $97(0.24)$ & $13(0.01)$ & $12(0.04)$ & $10(0.03)$ \\
North-eastern & 360 & $165(0.52)$ & $63(0.19)$ & $105(0.22)$ & $6(0.01)$ & $13(0.04)$ & $8(0.02)$ \\
Southern & 324 & $151(0.66)$ & $83(0.14)$ & $65(0.16)$ & $13(0.01)$ & $9(0.02)$ & $3(0.01)$ \\
\hline Total & 1032 & $487(0.53)$ & $191(0.19)$ & $267(0.20)$ & $32(0.02)$ & $34(0.04)$ & $21(0.02)$ \\
\hline
\end{tabular}

" Genotype refers to the homozygous and heterozygous cMDH gene: S, M, and F refer to Slow, Medium, and Fast alleles, respectively; SS = homozygous Slow genotype; SM = heterozygous Slow Medium genotype; etc.

Table 2 cMDH allele frequencies, observed heterozygosity (Ho), expected heterozygosity ( $\mathrm{He}$ ), and the subpopulation fixation index $\left(F_{\mathrm{IS}}\right)$ in the honey bee populations in Thailand. The allele frequencies in the queen breeding population in the United States (Shiff and Sheppard 1996) are given for references. Numbers in parentheses represent the standard errors.

\begin{tabular}{|c|c|c|c|c|c|c|c|}
\hline \multirow[t]{2}{*}{ Locality } & \multicolumn{3}{|c|}{ cMDH allele frequencies } & \multirow[t]{2}{*}{ Ho } & \multirow[t]{2}{*}{$\mathrm{He}$} & \multirow[t]{2}{*}{$F_{\text {IS }}$} & \multirow[t]{2}{*}{$F_{\mathrm{ST}}$} \\
\hline & $S$ & $\mathrm{M}$ & $\mathrm{F}$ & & & & \\
\hline Northern region $(\mathrm{n}=348)$ & 0.72 & 0.11 & 0.17 & 0.483 & 0.390 & -0.238 & \\
\hline North-eastern region $(n=360)$ & 0.72 & 0.13 & 0.15 & 0.567 & 0.515 & -0.100 & \\
\hline Southern region $(n=324)$ & 0.81 & 0.09 & 0.10 & 0.370 & 0.393 & 0.058 & \\
\hline Total $(\mathrm{n}=1032)$ & 0.73 & 0.13 & 0.14 & $\begin{array}{c}0.473 \\
(0.057)\end{array}$ & $\begin{array}{c}0.433 \\
(0.041)\end{array}$ & $\begin{array}{c}-0.094 \\
(0.085)\end{array}$ & 0.010 \\
\hline United States queen breeding population $(\mathrm{n}=356)$ & 0.70 & 0.08 & 0.22 & & & & \\
\hline
\end{tabular}

Table 3 Pearson correlation coefficients (probability in brackets) for cMDH allele and genotype frequencies, minimum and maximum temperatures in January and May with A. mellifera cMDH allele frequency for the eleven provinces of collection sites in Thailand (Table S1).

\begin{tabular}{lccccc}
\hline Allele/ & \multicolumn{2}{c}{ January } & & \multicolumn{2}{c}{ May } \\
\cline { 2 - 3 } \cline { 5 - 6 } Genotype & $\min$ & $\max$ & $\min$ & $\max$ \\
\hline F allele & -0.383 & -0.260 & & 0.204 & 0.325 \\
& $(0.246)$ & $(0.440)$ & & $0.547)$ & $(0.330)$ \\
M allele & 0.343 & 0.477 & 0.286 & -0.032 \\
& $(0.302)$ & $(0.138)$ & & $0.394)$ & $(0.925)$ \\
S allele & 0.193 & -0.318 & -0.556 & -0.495 \\
& $(0.569)$ & $(0.341)$ & & $(0.076)$ & $(0.121)$ \\
FF genotype & -0.254 & -0.236 & 0.276 & 0.321 \\
& $(0.452)$ & $(0.484)$ & & $(0.412)$ & $(0.336)$ \\
MM genotype & 0.210 & 0.577 & 0.391 & 0.183 \\
& $(0.535)$ & $(0.063)$ & $(0.234)$ & $(0.590)$ \\
SS genotype & 0.104 & -0.317 & -0.501 & -0.377 \\
& $(0.762)$ & $(0.343)$ & $(0.116)$ & $(0.253)$ \\
SM genotype & 0.430 & 0.423 & 0.169 & -0.170 \\
& $(0.186)$ & $(0.195)$ & $(0.619)$ & $(0.618)$ \\
SF genotype & -0.327 & -0.296 & 0.093 & 0.170 \\
& $(0.326)$ & $(0.378)$ & $(0.785)$ & $(0.618)$ \\
MF genotype & 0.047 & 0.074 & 0.116 & -0.126 \\
& $(0.890)$ & $(0.829)$ & $(0.735)$ & $(0.712)$ \\
\hline
\end{tabular}

Correlation is significant at the 0.05 level (2-tailed).

11 provinces where samples were collected (Table 3 ). This is probably due to the quite similar temperatures across the sampled areas.

\section{Appendix A. Supplementary data}

Supplementary data associated with this article can be found at http://dx.doi.org/10.2306/scienceasia1513-1874. 2022.015 .

Acknowledgements: We would like to thank members of the Behavior and Genetics of Social Insects Lab for assistance in laboratory experiments. This research was supported by Science Achievement Scholarship of Thailand, SAST (no. 0517.091/SAST 1293), Chulalongkorn University Ratchadaphiseksomphot Endownment Fund (the 90th Anniversary fund and the Postdoctoral Fellowship), and the Australian Research Council projects DP180101696 and DP190101500.

\section{REFERENCES}

1. Minárik P, Tomášková N, Kollárová M, Antalik M (2002) Malate dehydrogenases - structure and function. Gen Physiol Biophys 21, 257-265.

2. Chapman ADM, Cortés A, Dafforn TR, Clarke AR, Brady RL (1999) Structural basis of substrate specificity in malate dehydrogenases: crystal structure of a ternary complex of porcine cytoplasmic malate dehydrogenase, $\alpha$-Ketomalonate and TetrahydoNAD11. J Mol Biol 285, 703-712.

3. Dong Y, Somero GN (2009) Temperature adaptation of cytosolic malate dehydrogenases of limpets (genus Lottia): differences in stability and function due to minor changes in sequence correlate with biogeographic and vertical distributions. J Exp Biol 212, 169-177.

4. Hines SA, Philipp DP, Childers WF, Whitt GS (1983) Thermal kinetic differences between allelic isozymes of malate dehydrogenase (Mdh-B locus) of largemouth bass, Micropterus salmoides. Biochem Genet 21, 1143-1151. 
5. Cornuet JM, Oldroyd BP, Crozier RH (1995) Unequal thermostability of allelic forms of malate dehydrogenase in honey bees. J Apic Res 34, 45-47.

6. Dong Y-W, Liao M-L, Meng X-L, Somero GN (2018) Structural flexibility and protein adaptation to temperature: Molecular dynamics analysis of malate dehydrogenases of marine molluscs. Proc Natl Acad Sci USA 115, 1274-1279.

7. Johnson R (2009) Incidence of Florida largemouth bass alleles in two northern Arkansas populations of largemouth bass, Micropterus salmoides lacepede. Am Midl Nat 152, 425-429.

8. Hatty S, Oldroyd BP (1999) Evidence for temperaturedependent selection for malate dehydrogenase allele frequencies in honeybee populations. J Hered 90, 565-568.

9. Philipp D, Childers W, Whitt G (1981) Management implications for different genetic stocks of largemouth bass (Micropterus salmoides) in the United States. Can J Fish Aquat Sci 38, 1715-1723.

10. Allen R, Johnson R (2009) Temporal changes of largemouth bass alleles in a northern Arkansas reservoir stocked with Florida bass. J Ark Acad Sci 63, 28-33.

11. Nunamaker RA, Wilson WT (1981) Comparison of MDH allozyme patterns in the African honey Bee (Apis mellifera adansonii L.) and the Africanized populations of Brazil. J Kans Entomol Soc 54, 704-710.

12. Cornuet JM (1979) The MDH system in honeybees of Guadeloupe. J Hered 70, 223-224.

13. Meemongkolkiat T, Allison J, Seebacher F, Lim J, Chanchao C, Oldroyd BP (2020) Thermal adaptation in the honeybee (Apis mellifera) via changes to the structure of malate dehydrogenase. J Exp Biol 223, jeb.228239.

14. Badino G, Celebrano G, Manino A (1983) Population structure and Mdh-1 locus variation in Apis mellifera ligustica. $J$ Hered 74, 443-446.
15. Nielsen D, Page RE, Crosland MWJ (1994) Clinal variation and selection of MDH allozymes in honey bee populations. Experientia 50, 867-871.

16. Sheppard WS, Berlocher SH (1984) Enzyme polymorphism in Apis mellifera from Norway. $J$ Apic Res 23, 64-69.

17. Michener CD (2000) The Bees of the World, The Johns Hopkins University Press, Maryland, USA.

18. Seanbualuang P (2012) Basic knowledge of beekeeping. NUJST 20, 93-100.

19. Suppasat T, Smith DR, Deowanish S, Wongsiri S (2007) Matrilineal origins of Apis mellifera in Thailand. Apidologie 38, 323-334.

20. Oldroyd BP, Cornuet JM, Rowe D, Rinderer TE, Crozier RH (1995) Racial admixture of Apis mellifera in Tasmania, Australia: similarities and differences with natural hybrid zones in Europe. Heredity 74, 315-325.

21. Smouse PE, Peakall R (2012) GenAlEx 6.5: genetic analysis in excel. population genetic software for teaching and research an update. Bioinformatics 28, 2537-2539.

22. Wright S (1978) Evolution and the Genetics of Populations, Vol 4, Variability within and among Natural Populations, University of Chicago Press, Chicago.

23. Schiff NM, Sheppard WS (1996) Genetic differentiation in the queen breeding population of the western United States. Apidologie 27, 77-86.

24. Nunamaker RA, Wilson WT, Haley BE (1984) Electrophoretic detection of Africanized honey bees Apis mellifera scutellata in Guatemala and Mexico based on malate dehydrogenase allozyme patterns. J Kans Entomol Soc 57, 622-631.

25. Steel RGD, Torrie JH (1980) Principles and Procedures of Statistics, McGraw-Hill Book Company, Inc., New York, USA. 


\section{Appendix A. Supplementary data}

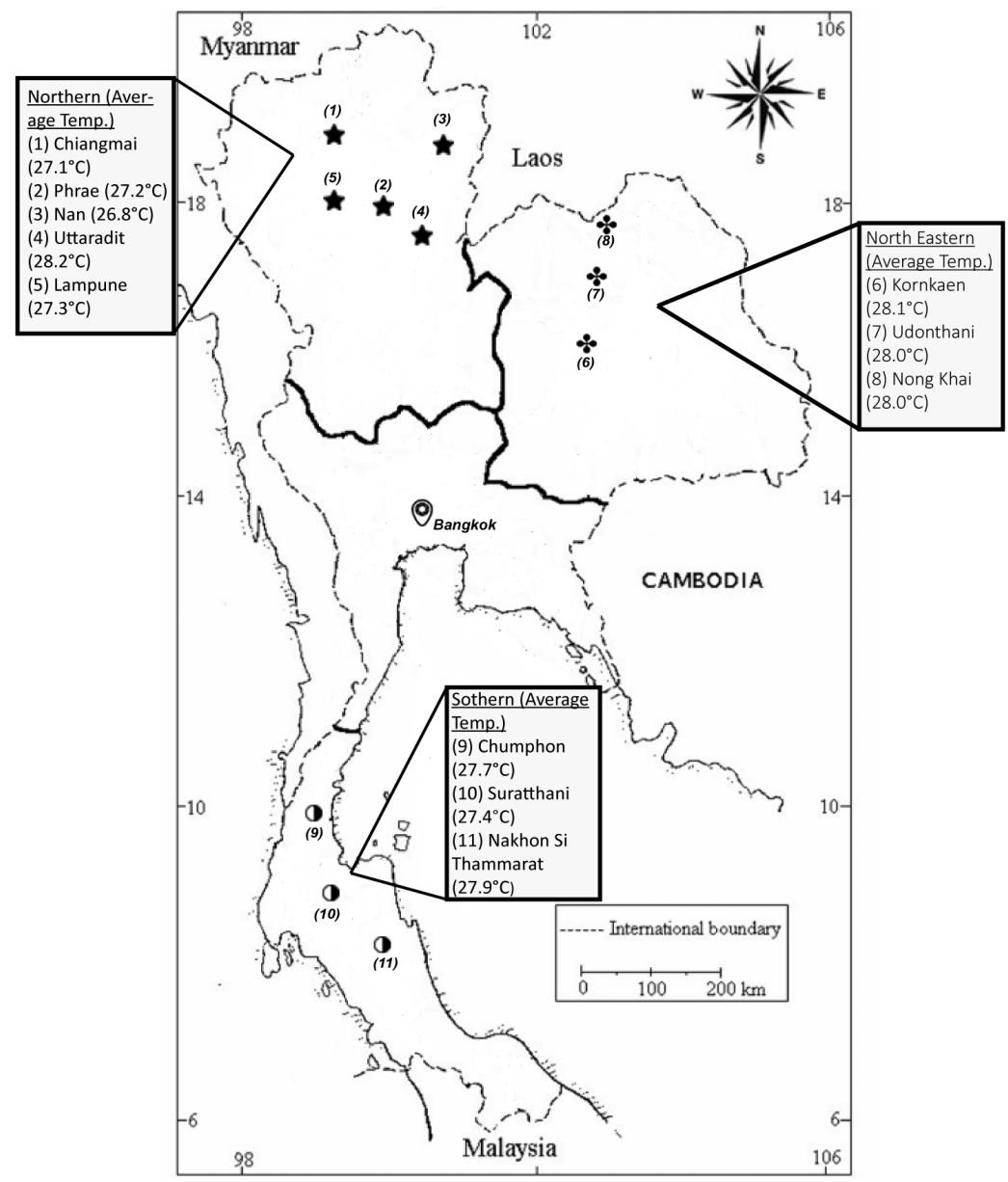

Fig. S1 Sampling sites for A. mellifera in Thailand. The numbers indicate collection sites. The boxes provide the names of provinces and the average temperature through the year in each region.

Table S1 Collection sites.

\begin{tabular}{|c|c|c|c|c|}
\hline \multirow[t]{2}{*}{ Region } & \multirow[t]{2}{*}{ Province } & \multirow{2}{*}{$\begin{array}{c}\text { No. } \\
\text { colonies }\end{array}$} & \multicolumn{2}{|c|}{ Coordinates } \\
\hline & & & Longitude & Latitude \\
\hline \multirow[t]{5}{*}{ Northern } & (1) Chiang Mai & 11 & $18^{\circ} 34^{\prime} 24.1^{\prime \prime} \mathrm{N}-18^{\circ} 44^{\prime} 20.2^{\prime \prime} \mathrm{N}$ & $98^{\circ} 48^{\prime} 12.4^{\prime \prime} \mathrm{E}-98^{\circ} 55^{\prime} 22.3^{\prime \prime} \mathrm{E}$ \\
\hline & (2) Phrae & 3 & $18^{\circ} 06^{\prime} 50.5^{\prime \prime} \mathrm{N}$ & $100^{\circ} 10^{\prime} 30.3^{\prime \prime} \mathrm{E}$ \\
\hline & (3) Nan & 3 & $19^{\circ} 10^{\prime} 35.0^{\prime \prime} \mathrm{N}$ & $100^{\circ} 55^{\prime} 14.3^{\prime \prime} \mathrm{E}$ \\
\hline & (4) Uttaradit & 3 & $17^{\circ} 41^{\prime} 25.4^{\prime \prime} \mathrm{N}$ & $100^{\circ} 09^{\prime} 01.0^{\prime \prime} \mathrm{E}$ \\
\hline & (5) Lamphun & 9 & $18^{\circ} 27^{\prime} 22.7^{\prime \prime} \mathrm{N}-18^{\circ} 30^{\prime} 57.4^{\prime \prime} \mathrm{N}$ & $98^{\circ} 54^{\prime} 56.0^{\prime \prime} \mathrm{E}-98^{\circ} 57^{\prime} 38.0^{\prime \prime} \mathrm{E}$ \\
\hline \multirow[t]{3}{*}{ North-eastern } & (6) Kornkaen & 10 & $16^{\circ} 27^{\prime} 05.0^{\prime \prime} \mathrm{N}-16^{\circ} 45^{\prime} 47.6^{\prime \prime} \mathrm{N}$ & $102^{\circ} 43^{\prime} 21.7^{\prime \prime} \mathrm{E}-103^{\circ} 00^{\prime} 06.5^{\prime \prime} \mathrm{E}$ \\
\hline & (7) Udonthani & 10 & $17^{\circ} 27^{\prime} 09.8^{\prime \prime} \mathrm{N}-17^{\circ} 28^{\prime} 27.8^{\prime \prime} \mathrm{N}$ & $102^{\circ} 49^{\prime} 52.5^{\prime \prime} \mathrm{E}-102^{\circ} 50^{\prime} 03.7^{\prime \prime} \mathrm{E}$ \\
\hline & (8) Nong Khai & 10 & $17^{\circ} 52^{\prime} 27.8^{\prime \prime} \mathrm{N}-17^{\circ} 54^{\prime} 14.8^{\prime \prime} \mathrm{N}$ & $102^{\circ} 30^{\prime} 37.7^{\prime \prime} \mathrm{E}-102^{\circ} 35^{\prime} 00.8^{\prime \prime} \mathrm{E}$ \\
\hline \multirow[t]{3}{*}{ Southern } & (9) Chumphon & 12 & $9^{\circ} 55^{\prime} 13.0^{\prime \prime} \mathrm{N}-10^{\circ} 14^{\prime} 35.2^{\prime \prime} \mathrm{N}$ & $99^{\circ} 01^{\prime} 05.2^{\prime \prime} \mathrm{E}-99^{\circ} 04^{\prime} 33.1^{\prime \prime} \mathrm{E}$ \\
\hline & (10) Suratthani & 10 & $8^{\circ} 55^{\prime} 32.8^{\prime \prime} \mathrm{N}-9^{\circ} 03^{\prime} 05.5^{\prime \prime} \mathrm{N}$ & $99^{\circ} 20^{\prime} 07.0^{\prime \prime} \mathrm{E}-99^{\circ} 24^{\prime} 45.6^{\prime \prime} \mathrm{E}$ \\
\hline & (11) Nakhon Si Thammarat & 5 & $8^{\circ} 46^{\prime} 42.2^{\prime \prime} \mathrm{N}-8^{\circ} 46^{\prime} 45.2^{\prime \prime} \mathrm{N}$ & $99^{\circ} 54^{\prime} 26.4^{\prime \prime} \mathrm{E}-99^{\circ} 54^{\prime} 28.4^{\prime \prime} \mathrm{E}$ \\
\hline
\end{tabular}

